\title{
Influence of Benz[a]anthracene on Bone Metabolism and on Liver Metabolism in Nibbler Fish, Girella punctata
}

\author{
Mohamed I. Zanaty ${ }^{1,2}$, Niina Sawada ${ }^{3}$, Yoichiro Kitani ${ }^{2,3}$, Hossam F. Nassar ${ }^{1}$,

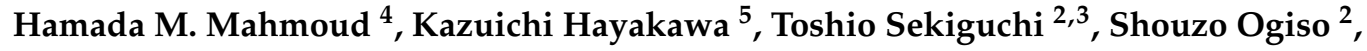 \\ Yoshiaki Tabuchi ${ }^{6}$, Makoto Urata ${ }^{2,7}$, Hajime Matsubara ${ }^{8}$ (D), Yutaka Takeuchi ${ }^{8}$, \\ Atsuhiko Hattori ${ }^{9}$, Ajai K. Srivastav ${ }^{10}$, Thumronk Amornsakun ${ }^{11}$ and Nobuo Suzuki ${ }^{2,3, *(D)}$ \\ 1 Faculty of Postgraduate Studies for Advanced Sciences, Beni-suef University, Beni-Suef 62511, Egypt; \\ zanaty012@yahoo.com (M.I.Z.); hossamnassarnrc@gmail.com (H.F.N.) \\ 2 Noto Marine Laboratory, Institute of Nature and Environmental Technology, Division of Marine \\ Environmental Studies, Kanazawa University, Noto-cho, Ishikawa 927-0553, Japan; \\ yki@se.kanazawa-u.ac.jp (Y.K.); t-sekiguchi@se.kanazawa-u.ac.jp (T.S.); \\ shozoogiso@se.kanazawa-u.ac.jp (S.O.); glandiceps@yahoo.co.jp (M.U.) \\ 3 School of Natural System, College of Science and Engineering, Kanazawa University, Kakuma-machi, \\ Kanazawa city, Ishikawa 920-1192, Japan; nobuosuzuki1964@gmail.com \\ 4 Faculty of Science, Beni-Suef University, Beni-Suef 62511, Egypt; mhmada@aucegypt.edu \\ 5 Low Level Radioactivity Laboratory, Institute of Nature and Environmental Technology, Kanazawa \\ University, Nomi city, Ishikawa 923-1224, Japan; hayakawa@p.kanazawa-u.ac.jp \\ 6 Division of Molecular Genetics Research, Life Science Research Center, University of Toyama, Sugitani, \\ Toyama 930-0194, Japan; ytabu@cts.u-toyama.ac.jp \\ 7 Institute of Noto SATOUMI Education Research, Noto-cho, Ishikawa 927-0553, Japan \\ 8 Noto Center for Fisheries Science and Technology, Kanazawa University, Ossaka, Noto-cho, \\ Ishikawa 927-0552, Japan; matsu@se.kanazawa-u.ac.jp (H.M.); yutaka@se.kanazawa-u.ac.jp (Y.T.) \\ 9 Department of Biology, College of Liberal Arts and Sciences, Tokyo Medical and Dental University, \\ Ichikawa city, Chiba 272-0827, Japan; ahattori.las@tmd.ac.jp \\ 10 Department of Zoology, D.D.U. Gorakhpur University, Gorakhpur 273-009, India; \\ ajaiksrivastav@hotmail.com \\ 11 Fisheries Technology Program, Faculty of Science and Technology, Prince of Songkla University, \\ Pattani 94000, Thailand; thumronk.a@psu.ac.th \\ * Correspondence: nobuos@staff.kanazawa-u.ac.jp; Tel.: +81-768-74-1151
}

Received: 12 December 2019; Accepted: 18 February 2020; Published: 21 February 2020

\begin{abstract}
It has been reported that spinal deformity was induced in developing fish by the addition of polycyclic aromatic hydrocarbons (PAHs). To examine the mechanism of the disruption of fish bone metabolism, the effect of benz $[a]$ anthracene $(\mathrm{BaA})$, a kind of $\mathrm{PAH}$, on plasma calcium, inorganic phosphorus, osteoblasts, and osteoclasts was investigated in this study. We also measured several plasma components to analyze the toxicity of BaA on other metabolisms. BaA ( 1 or $10 \mathrm{ng} / \mathrm{g}$ body weight) was intraperitoneally injected (four times) into nibbler fish during breeding, for 10 days, and it was indicated, for the first time, that injecting high doses of BaA to nibbler fish induced both hypocalcemia and hypophosphatemia. Furthermore, in the scales of nibbler fish treated with high doses of $\mathrm{BaA}$, both osteoclastic and osteoblastic marker messengerRNA (mRNA) expressions decreased. These results are a cause of disruption of bone metabolism and, perhaps, the induction of spinal deformities. In addition, we found that total protein, metabolic enzymes in the liver, total cholesterol, free cholesterol, and high-density lipoprotein cholesterol levels significantly decreased in BaA-injected fish. These results indicate that BaA may affect liver diseases and emphasize the importance of prevention of aquatic $\mathrm{PAH}$ pollution.
\end{abstract}


Keywords: benz[a]anthracene; fish scales; osteoblasts; osteoclasts; calcium; inorganic phosphorus; liver metabolism; marine fish

\section{Introduction}

Polycyclic aromatic hydrocarbons (PAHs) are a series of organic compounds that are atmospheric environmental pollutants derived from petroleum and produced by the incomplete combustion of fossil fuel, wood, and other organic materials [1], as well as cigarette smoke [2]. It has been reported that PAHs affect bone metabolism in mammals. For example, PAHs (benzo[a]pyrene (BaP); 7,12-dimethylbenz [a]anthracene (DMBA)) contained in cigarette smoke induced a loss of bone mass and bone strength, possibly through an increase in bone turnover [2]. In humans, furthermore, associations between urinary PAH content and bone mass density were stronger for postmenopausal women when compared with the premenopausal group [3]. Atmospheric PAHs seem to influence bone metabolism in terrestrial animals, including humans.

In the aquatic environment as well as the atmospheric environment, aquatic PAH contamination derived from storm water runoff and atmospheric deposition is evident $[1,4]$ and bone deformity induced by PAHs has been observed in pacific herring, pink salmon and zebrafish $[5,6]$, although the underlying mechanism has not yet been fully elucidated. Therefore, we should be giving greater attention to bone metabolism in aquatic animals such as fish.

On the other hand, teleosts have a calcified organ-scales-that possesses osteoclasts, osteoblasts, and a calcified bone matrix [7-11]. Fish scales are a potential internal calcium reservoir other than vertebral bone [7,12]. In the case of mercury, a significant co-relationship between mercury levels in the scales and in the muscles was reported in the largemouth bass [13], although mercury did not accumulate in the vertebral bone of the fish [14]. Furthermore, fish scales have been used for reconstructing past contamination in aquatic systems [15]. This indicates that scales are more active than vertebral bone in bone metabolism. In addition, we have previously found an estrogenic effect on the mono-hydroxylated form of benz[a]anthracene $(\mathrm{BaA})[16]$, but not on that of $\mathrm{BaP}$, and reported that mono-hydroxylated BaA suppressed osteoblastic and osteoclastic activities in goldfish scales [17].

Thus, in the present study, we examined plasma calcium (Ca) and inorganic phosphorus (Pi) levels and both scale osteoclastic and osteoblastic activities after injecting a low level of benz[a]anthracene (BaA) (1 or $10 \mathrm{ng} / \mathrm{g}$ body weight) into marine teleosts, nibbler fish (Girella punctata). Furthermore, we measured several plasma components to analyze the toxicity of BaA on other metabolisms.

The present study is the first to demonstrate that BaA decreases both plasma Ca and Pi levels in marine teleosts resulting from the influence of the osteoclasts and osteoblasts of nibbler fish scales. In addition, our data suggest that $\mathrm{BaA}$ induces liver diseases in addition to bone diseases.

\section{Materials and Methods}

\subsection{Animals}

The nibbler fish (Girella punctata) is a member of the Kyphosidae family and is a seawater fish distributed in the warm shallow waters of East Asia. It is easy to collect by fishing around our research institute and for this reason, we used it in the present study. Nibbler fish (both sexes, $n=24$, $54.5 \pm 3.5 \mathrm{~g}$, around 1 to 2 years old) were captured by fishing in Tsukumo Bay of the Noto Peninsula (Ishikawa Prefecture). After acclimation for approximately 2 weeks, these fish were used in the present experiments.

All experimental procedures were conducted in accordance with the Kanazawa University Guide for the Care and Use of Laboratory Animals. 


\subsection{Effects of BaA on Plasma Ca and Pi Levels in Nibbler Fish}

Nibbler fish were divided into three groups (eight individuals each) and anesthetized with $0.04 \%$ of a 2-phenoxyethanol (FUJIFILM Wako Pure Chemical Corporation, Osaka, Japan), and BaA (FUJIFILM Wako Pure Chemical Corporation) (low dose: $1 \mathrm{ng} / \mathrm{g}$ of body weight, $\mathrm{n}=8$; high dose: $10 \mathrm{ng} / \mathrm{g}$ body weight, $\mathrm{n}=8$ ) was injected intraperitoneally. These concentrations were determined based on the sea water which is highly contaminated with PAHs (total PAHs: 0.99-1.36 ng/mL) [18]. The injection was performed four times (on days 1, 3, 6, and 9). BaA was first dissolved in dimethyl sulfoxide (DMSO), and then distilled water was added to the DMSO solution so that the DMSO concentration became $0.5 \%$. Nibbler fish in the control group $(n=8)$ were injected with $0.5 \%$ DMSO solution in the same manner as were the experimental nibbler fish. These fish were kept in one aquarium per respective treatment for 10 days at $26^{\circ} \mathrm{C}$ under a $12 \mathrm{~h} \mathrm{light} / 12 \mathrm{~h}$ dark cycle while adding a small amount of natural seawater. The amount of PAHs in the seawater used in the present study was less than $2 \mathrm{pg} / \mathrm{mL}$ [19]. The values of $\mathrm{pH}$ and the salinity of the seawater were stable at around 8.25-8.35 and 33.0-33.5 practical salinity units, respectively. During the experimental periods, fish were fed every morning. Ten days after breeding, these fish were anesthetized again with $0.04 \%$ of a 2-phenoxyethanol. Blood samples from anesthetized nibbler fish were collected from their caudal vessels using a heparinized syringe. The collected blood was put into a $1.5 \mathrm{~mL}$ tube. Thereafter, the tube was centrifuged at 15,000 rpm for $3 \mathrm{~min}$. The separated plasma was immediately frozen and kept at $-80^{\circ} \mathrm{C}$ until use. The plasma total Ca levels $(\mathrm{mg} / \mathrm{dL}$ ) were determined using an assay kit (Calcium E, FUJIFILM Wako Pure Chemical Corporation) as described in Suzuki et al. (2017) [20] and Sato et al. (2017) [21]. The plasma Pi levels (mg/dL) were measured using an assay kit (IP-II, Kyowa MEDEX Co., Ltd., Tokyo, Japan). Ten days after $\mathrm{BaA}$ injection, scales on the right side were extracted from anesthetized nibbler fish to examine the influences of $\mathrm{BaA}$ on the osteoblasts and osteoclasts. The collected scales were frozen at $-80^{\circ} \mathrm{C}$ for messengerRNA (mRNA) analysis.

\subsection{Osteoblastic and Osteoclastic Marker mRNA Expression in BaA-Treated Nibbler Fish Scales}

Total RNAs were prepared from nibbler fish scales (in all three groups, $\mathrm{n}=8$ ) kept in one aquarium per respective treatment using a total RNA isolation kit (NucleoSpin RNA II, Takara Bio Inc., Otsu, Japan). Complementary DNA synthesis was performed using a kit (PrimeScript ${ }^{\mathrm{TM}}$ II 1st strand cDNA Synthesis Kit, Takara Bio Inc., Kusatsu, Japan). Gene-specific primers for matrix metalloproteinase- 9 (MMP-9) [21] and collagen, type 1, $\alpha 1$ (COL1A1) [22] are indicated in Table 1. Elongation factor- $1 \alpha$ $($ EF-1 $\alpha$ ) cDNA was amplified using a primer set [22] (Table 1). The PCR amplification was analyzed using a real-time PCR apparatus (Mx3000p, Agilent Technologies, Santa Clara, CA, USA) [21,23]. The annealing temperature of MMP-9, COL1A1, and EF- $1 \alpha$ was $60^{\circ} \mathrm{C}$. The MMP-9 and COL1A1 mRNA levels were normalized to the EF-1 $\alpha$ mRNA level [24].

Table 1. Primer sequences for real-time quantitative PCR.

\begin{tabular}{llll}
\hline Name & Forward Primer & Reverse Primer & Accession Number \\
\hline MMP-9 & TGTGGTGCTCAACCACCTACAACT & ATCCCTGCCTTGAGTGGTGCAT & LC198841 \\
COL1A1 & GTGAGGTCGCCAAGAAGAAC & ATGAGACGCAGGAAGGTCAG & AB874603 \\
EF-1 $\alpha$ & GTATGGTCGTCACCTTTGCTC & GTGGGTCGTTCTTGCTGTC & AB874605 \\
\hline & MMP-9: matrix metalloproteinase-9; COL1A1: collagen, type 1, $\alpha 1 ;$ EF-1 $\alpha$ : elongation factor-1 $\alpha$.
\end{tabular}

\subsection{Measurement of Plasma Components in BaA-Injected and Untreated Nibbler Fish}

In each group $(\mathrm{n}=8)$, plasma samples in the BaA-treated or untreated nibbler fish were sent to a commercial vendor (Oriental Yeast Co., Ltd., Tokyo, Japan) for analysis. Total protein, albumin, alkaline phosphatase (ALP) activity, lactate dehydrogenase (LDH) activity, aspartate transaminase (AST) activity, leucine aminopeptidase (LAP) activity, total-cholesterol (T-CHO), free-cholesterol (F-CHO), ester type-cholesterol (E-CHO), and triglyceride (TG) were measured using several kits (FUJIFILM 
Wako Pure Chemical Corporation). Kits from Sekisui Medical Co. were used to determine low-density lipoprotein cholesterol (LDL-C) and high-density lipoprotein cholesterol (HDL-C). Sodium (Na), chlorine $(\mathrm{Cl})$, and potassium $(\mathrm{K})$ in the plasma of BaA-treated or untreated nibbler fish were measured by an ion electrode method with a Hitachi 7180 automatic analyzer (Hitachi High Technologies Corporation, Tokyo, Japan).

\subsection{Statistical Analysis}

All results are expressed as the means \pm standard error (SE). The statistical significance between the control and experimental groups was assessed using a one-way ANOVA followed by Dunnett's test or Student's $t$-test. In all cases, the selected significance level was $p<0.05$.

\section{Results}

\subsection{Effects of BaA on Plasma Ca and Pi Levels in BaA-Treated or Untreated Nibbler Fish}

Figure $1 \mathrm{a}$ indicates the result of plasma Ca levels after intraperitoneal BaA injection. BaA (low dose: $1 \mathrm{ng} / \mathrm{g}$ of body weight) tended to decrease. The higher dose (10 ng/g of body weight) of BaA induced significant hypocalcemia.

Furthermore, plasma Pi levels decreased with the low dose of BaA treatment, although there was not a significant difference between the experimental and control groups (Figure $1 \mathrm{~b}$ ). In the case of the higher dose, plasma Pi levels decreased significantly (Figure 1b).

(a) Plasma Ca

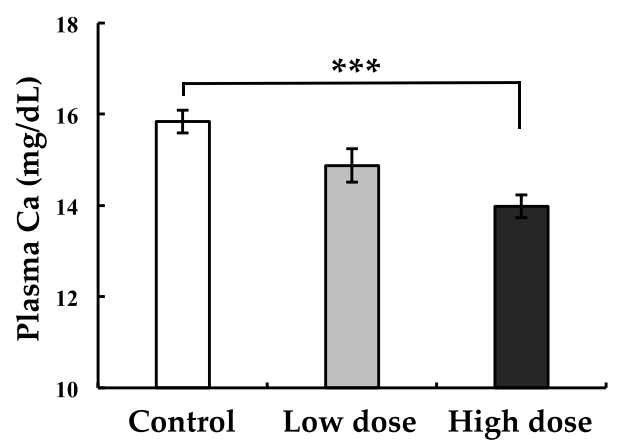

\section{(b) Plasma Pi}

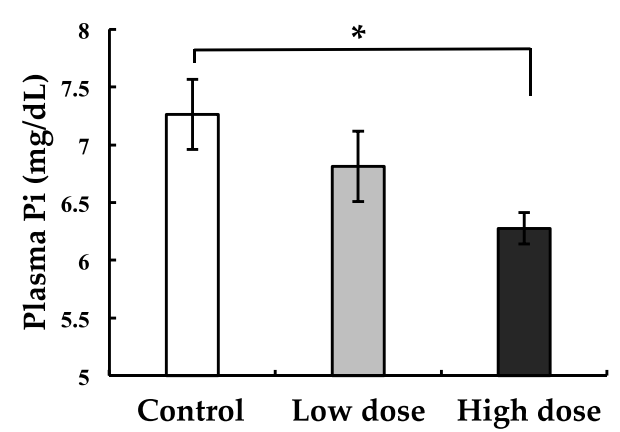

Figure 1. Effects of $\mathrm{BaA}$ on plasma calcium (Ca) (a) and inorganic phosphorus (Pi) (b) levels in BaA-treated or untreated nibbler fish. BaA (1 or $10 \mathrm{ng} / \mathrm{g}$ body weight) was injected intraperitoneally (four times) into nibbler fish for 10 days during breeding. Thereafter, plasma Ca and Pi levels were examined in the control and experimental groups. ${ }^{*}$ and ${ }^{* * *}$ indicate statistically significant differences at $p<0.05$ and $p<0.001$, respectively, from the values in the control scales $(\mathrm{n}=8)$. The detection limits of Plasma Ca and Pi were 0.4 and $0.04 \mathrm{mg} / \mathrm{dL}$, respectively.

3.2. Effects of BaA on Osteoclastic and Osteoblastic Marker mRNA Expression in The Scales of BaA-Treated or Untreated Nibbler Fish

At the higher dose (10 ng/g of body weight), BaA induced significant hypocalcemia and hypophosphatemia. Therefore, we examined the effect of $\mathrm{BaA}$ at the high dose on osteoclasts and osteoblasts of the scales of BaA-injected nibbler fish in an in vivo experiment.

Osteoclastic marker (MMP9) mRNA expression results are shown in Figure 2a. BaA suppressed MMP9 mRNA expression. The mRNA expression of osteoblastic marker COL1A1 also decreased significantly (Figure 2b). 
(a) Osteoclastic marker

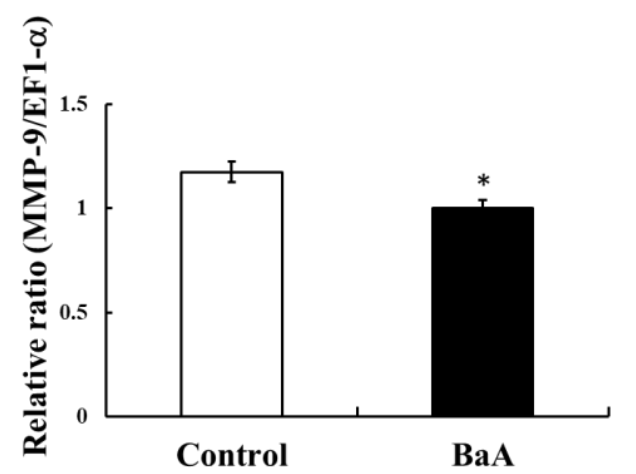

(b) Osteoblastic marker

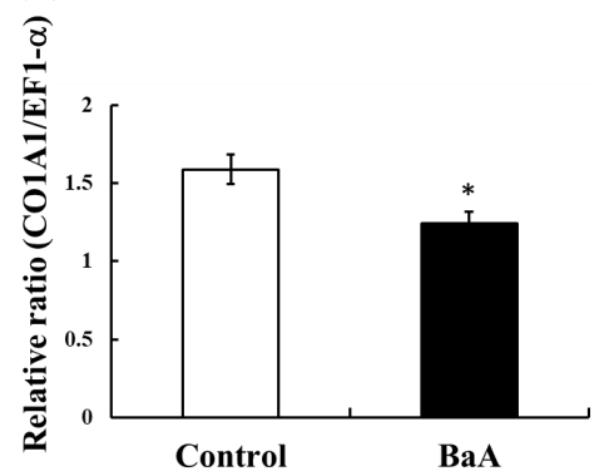

Figure 2. Effects of BaA on osteoclastic (a) and osteoblastic (b) marker messengerRNA (mRNA) expression in the scales of BaA-treated or untreated nibbler fish. BaA (10 ng/g body weight) was injected intraperitoneally (four times) into nibbler fish for 10 days during breeding. Thereafter, osteoclastic and osteoblastic marker mRNA expressions were examined in the control and experimental groups. * indicates a statistically significant difference at $p<0.05$ from the values in the control scales $(\mathrm{n}=8)$.

\subsection{Effects of BaA on Total Protein and Albumin in The Plasma of BaA-Treated or Untreated Nibbler Fish}

In order to perform a comprehensive analysis of blood components, we first analyzed total protein and albumin in the plasma of nibbler fish. At low dose exposure, total protein levels in BaA-treated nibbler fish were not changed as compared to those in control nibbler fish (Figure 3a). However, a significant difference in the total protein levels between nibbler fish treated with the high dose of $\mathrm{BaA}$ and control nibbler fish was obtained (Figure 3a). Also, albumin levels tended to decrease when treated with low and high doses of $\mathrm{BaA}$, although there was no significant difference in the albumin levels of BaA-treated and control groups (Figure 3b).

(a) Total protein

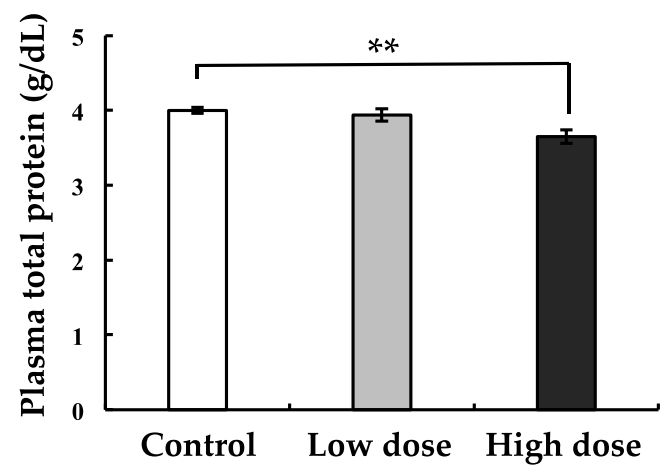

(b) Albumin

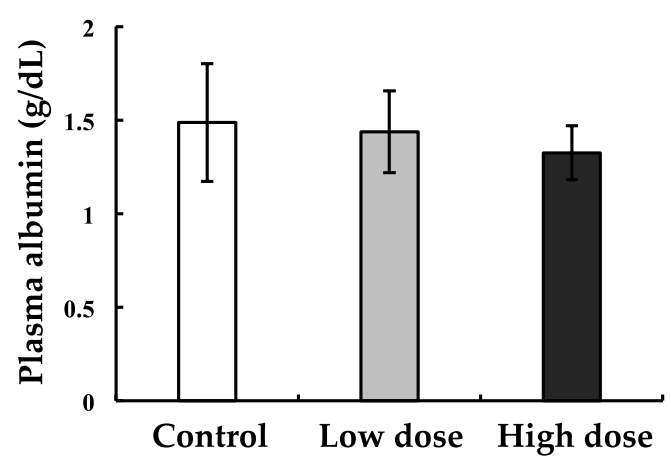

Figure 3. Effect of BaA on total protein (a) and albumin (b) in the plasma of BaA-treated or untreated nibbler fish. BaA (1 or $10 \mathrm{ng} / \mathrm{g}$ body weight) was injected intraperitoneally (four times) into nibbler fish for 10 days during breeding. Thereafter, total protein and albumin were examined in the control and experimental groups. ${ }^{* *}$ indicates a statistically significant difference at $p<0.01$ from the values in the control scales $(n=8)$. The detection limits of total protein and albumin were 1.0 and $1.0 \mathrm{~g} / \mathrm{dL}$, respectively.

\subsection{Changes in The Enzyme Markers of The Liver with BaA Treatment}

We noted that the liver is a target organ for BaA because total protein and albumin decreased as shown in Figure 1. To examine the influence of BaA on liver diseases, the blood marker enzyme activities for ALP, LDH, AST, and LAP were measured in the plasma of BaA-treated nibbler fish or untreated nibbler fish. Data are shown in Figure 4. 


\section{(a) ALP}

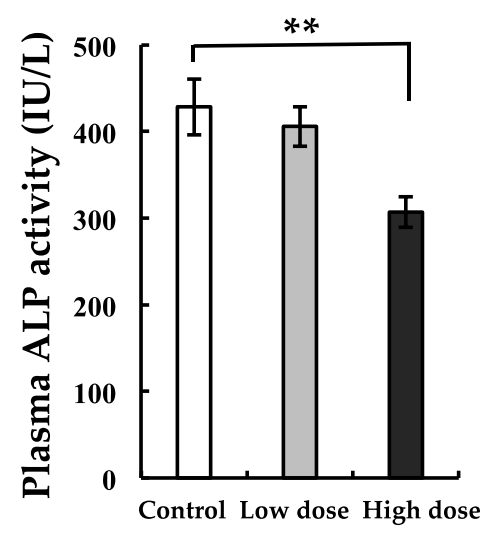

(c) AST

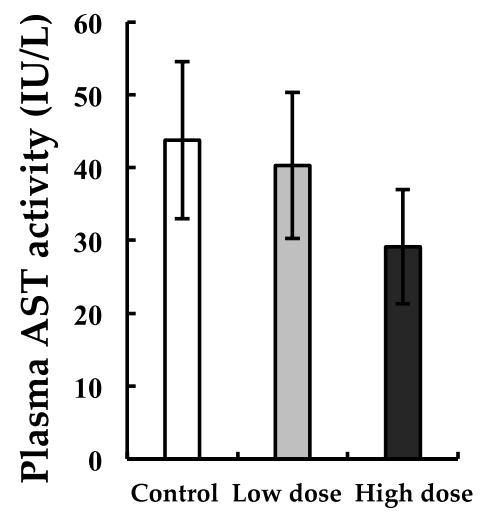

(b) LDH

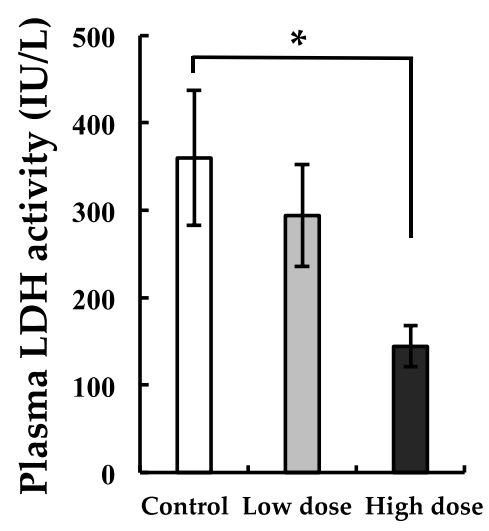

(d) LAP

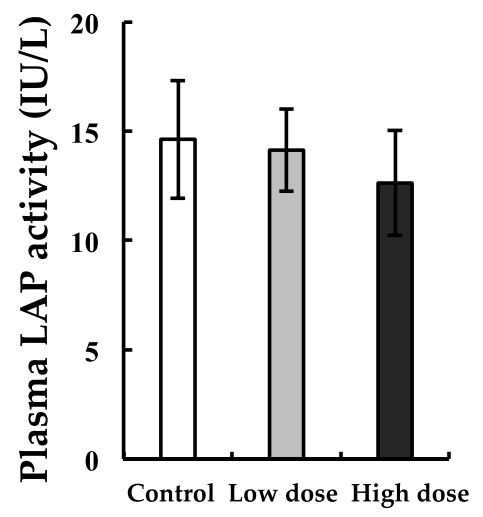

Figure 4. Changes in alkaline phosphatase (ALP) (a), lactate dehydrogenase (LDH) (b), aspartate transaminase (AST) (c), and leucine aminopeptidase (LAP) (d) of the liver with BaA treatment. BaA (1 or $10 \mathrm{ng} / \mathrm{g}$ body weight) was injected intraperitoneally (four times) into nibbler fish for 10 days during breeding. Thereafter, plasma liver markers were examined in the control and experimental groups. * and ${ }^{* *}$ indicate statistically significant differences at $p<0.05$ and $p<0.01$, respectively, from the values in the control scales $(n=8)$. The detection limits of ALP, LDH, AST, and LAP were 2, 6, 3, and $0.4 \mathrm{IU} / \mathrm{L}$, respectively.

In the low-dose group, all markers tended to decrease. Significant differences in the ALP and $\mathrm{LDH}$ of the plasma of BaA-treated nibbler fish as compared with that of untreated nibbler fish were observed at the high dose. The remarkable suppression of ALP was obtained at the high dose.

\subsection{Changes in Markers of Lipid Metabolism with BaA Treatment}

In the low-dose group, T-CHO, E-CHO, LDH-C, and HDH-C tended to decrease, although there were no significant differences between the experimental and control groups (Figure 5). In the high-dose group, F-CHO levels were largely suppressed. Other markers (T-CHO and HDL-C) decreased significantly in nibbler fish treated with the high dose of BaA (Figure 5). 
(a) $\mathrm{T}-\mathrm{CHO}$
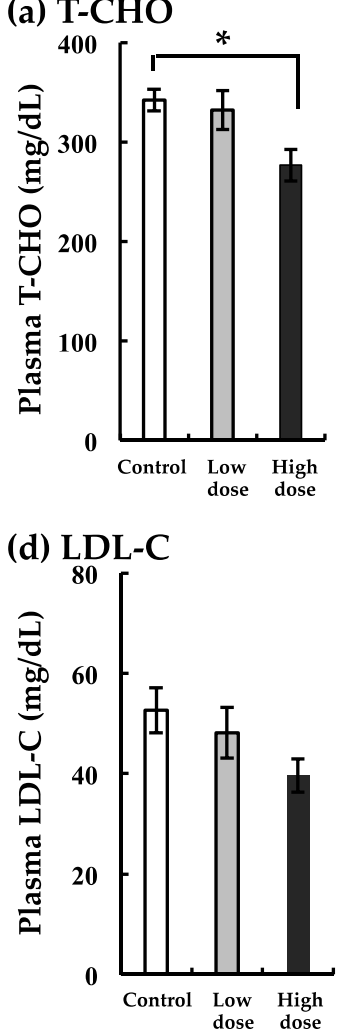

(b) $\mathrm{F}-\mathrm{CHO}$

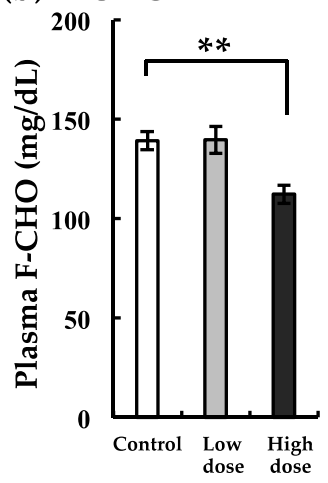

(e) HDL-C

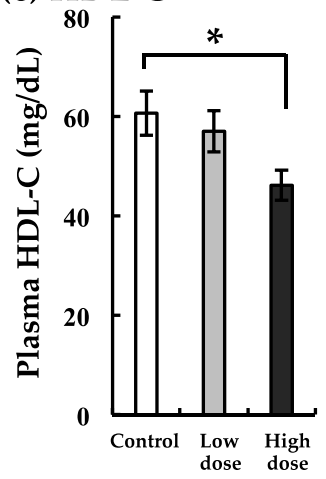

(c) $\mathrm{E}-\mathrm{CHO}$

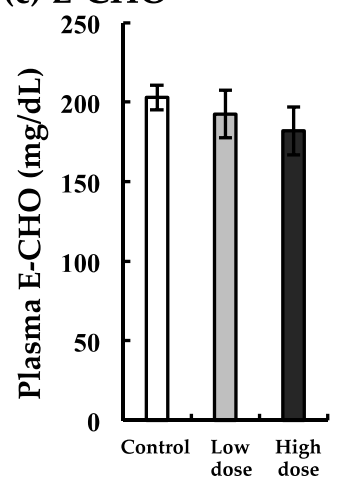

(f) TG

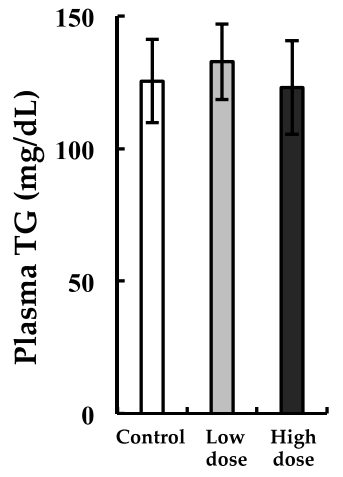

Figure 5. Changes in total-cholesterol (T-CHO) (a), free-cholesterol (F-CHO) (b), ester type-cholesterol $(\mathrm{E}-\mathrm{CHO})(\mathrm{c})$, low-density lipoprotein cholesterol (LDL-C) (d), high-density lipoprotein cholesterol (HDL-C) (e), and triglyceride (TG) (f) with BaA treatment. BaA (1 or $10 \mathrm{ng} / \mathrm{g}$ body weight) was injected intraperitoneally (four times) into nibbler fish for 10 days during breeding. Thereafter, plasma lipid markers were examined in the control and experimental groups. ${ }^{*}$ and ${ }^{* *}$ indicate statistically significant differences at $p<0.05$ and $p<0.01$, respectively, from the values in the control scales $(\mathrm{n}=8)$. The detection limits of T-CHO, F-CHO, LDL-C, HDL-C, and TG were 1, 1, 1, 2, and $2 \mathrm{mg} / \mathrm{dL}$, respectively.

\subsection{Changes in $\mathrm{Na}, \mathrm{K}$, and $\mathrm{Cl}$ Levels with $\mathrm{BaA}$ Treatment}

Plasma $\mathrm{Na}, \mathrm{K}$, and $\mathrm{Cl}$ levels were decreased slightly with both low and high doses of BaA (Figure 6). In these minerals, there was no significant difference between the experimental and control groups (Figure 6).
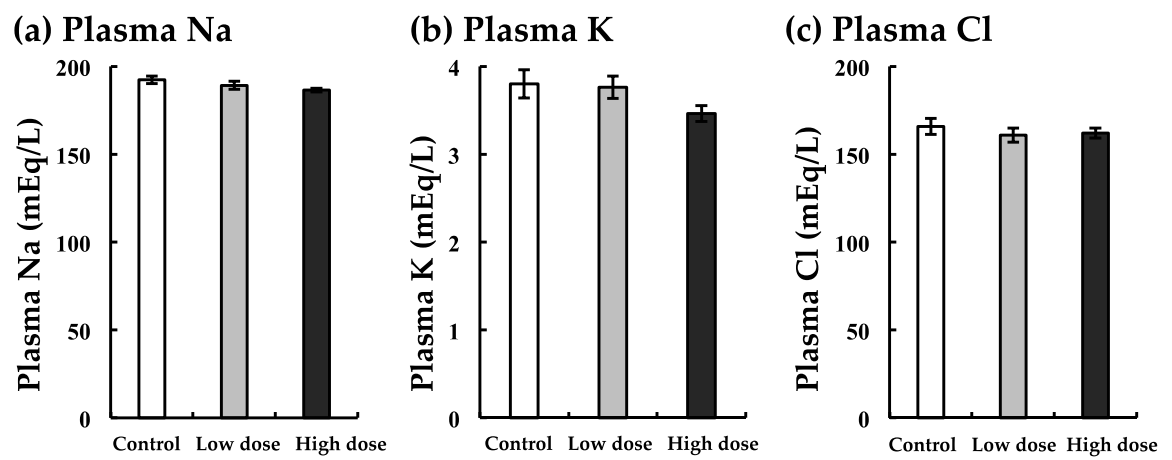

Figure 6. Changes in $\mathrm{Na}(\mathbf{a}), \mathrm{K}(\mathbf{b})$, and $\mathrm{Cl}$ (c) levels with BaA treatment. $\mathrm{BaA}$ (1 or $10 \mathrm{ng} / \mathrm{g}$ body weight) was injected intraperitoneally (four times) into nibbler fish for 10 days during breeding. Thereafter, plasma $\mathrm{Na}, \mathrm{K}$, and $\mathrm{Cl}$ were examined in the control and experimental groups. There was no significant difference between the control and experimental groups $(n=8)$. The detection limits of $\mathrm{Na}, \mathrm{K}$, and $\mathrm{Cl}$ were 10,1 , and $10 \mathrm{mEq} / \mathrm{L}$, respectively. 


\section{Discussion}

We are the first to demonstrate that $\mathrm{BaA}$ decreased both plasma $\mathrm{Ca}$ and Pi levels in marine teleosts. We previously reported that BaA induced hypocalcemia at 24 and $48 \mathrm{~h}$ after injection into goldfish (freshwater fish) [20]. In our previous study, we could not measure the plasma Pi level. It is well known that $\mathrm{Ca}$ and $\mathrm{Pi}$ are bone components. In addition to the plasma Ca concentrations, we found that the plasma Pi concentrations also decreased after injection of BaA into nibbler fish. Furthermore, the mineral concentrations of $\mathrm{Na}, \mathrm{K}$, and $\mathrm{Cl}$ did not change significantly with $\mathrm{BaA}$ treatment. Taking these results into consideration, $\mathrm{BaA}$ has a specific effect on bone mineral metabolism. Through these specific effects, we concluded that PAHs induced bone deformities in teleosts such as Pacific herring, pink salmon, and sea bass $[5,25]$.

We discovered the toxicity of mono-hydroxylated polycyclic aromatic hydrocarbons (OHPAHs), metabolites of PAHs, in osteoclasts and osteoblasts of fish scales [17]. Namely, 4-hydroxybenz[a]anthracene (4-OHBaA) suppressed both tartrate-resistant acid phosphatase and ALP activities in the cultured scales of goldfish (freshwater teleost) and wrasse (marine teleost) [17]. In fact, 4-OHBaA, which is one of the metabolites of BaA by a conversion enzyme (P4501A1), was detected in the bile of goldfish at 12, 24, 48, and $72 \mathrm{~h}$ after the administration of $\mathrm{BaA}$ into these goldfish [20]. In nibbler fish, OHBaA, metabolites of $\mathrm{BaA}$, suppressed osteoclasts and osteoblasts. The suppression of both an osteoclastic marker (MMP9) and an osteoblastic marker (COL1A1) coincided with the action of 4-OHBaA [17]. In mammals, PAHs (BaP and DMBA) present in cigarette smoke induced bone loss in an ovariectomized rat [2]. In addition, $\mathrm{BaP}$ inhibited osteoclastogenesis in rabbit osteoclasts and RAW264.7 cells (a mouse monocyte macrophage cell line) [26]. Although PAHs are known to bind to the aryl hydrocarbon receptor [6,26], their subsequent action mechanism is unknown. In mammals as well as teleosts, OHPAHs converted from PAH may disrupt bone metabolism. To elucidate the further mechanism of PAH toxicity on bone metabolism, we are planning to examine the influence of OHPAH on a mammalian osteoblastic cell line.

In order to perform a comprehensive analysis of blood components, we analyzed total protein and albumin in the plasma of nibbler fish. A significant difference in total protein levels between nibbler fish treated with the higher dose of $\mathrm{BaA}$ and control nibbler fish was obtained. Also, albumin levels decreased in a dose-dependent manner. Nutritionally, BaA may have adverse effects on fish because $\mathrm{BaA}$ acts on the liver metabolism, such as $\mathrm{LDH}$ and cholesterol metabolism. BaP has been identified as being highly carcinogenic $[27,28]$. BaP showed strong repression of genes involved in cholesterol and fatty acid biosynthesis [29]. However, BaA did not influence TG levels, although BaA decreased T-CHO, F-CHO, E-CHO, LDH-C, and HDH-C. The action mechanisms of BaP and BaA may thus be different. In addition, we found that ALP activity appeared to have decreased remarkably. ALP activity is also known as an osteoblastic marker [11,21,30], although ALP is a marker of liver diseases [31,32]. In the present study, we indicated that the mRNA expression of the osteoblastic marker COL1A1 decreased significantly. Under the influence of both bone and liver, ALP activity appeared to have decreased remarkably.

We can analyze the influence of BaA on osteoblasts and osteoclasts using in vitro cultured fish scales. The teleost fish has a unique hard tissue, scales that consist of osteoblasts, osteoclasts, and calcified bone matrix, including type 1 collagen, bone $\gamma$-carboxyglutamic acid protein, osteonectin, and hydroxyapatite [11,33]. In addition, teleost scales, like the mammalian endoskeleton, are known to work as a potential internal calcium reservoir [11,33]. From morphological observation, we demonstrated that the osteogenesis of regenerating scale is quite similar to that of mammalian membrane bone [34]. Furthermore, the fine structure of osteoclasts and osteoblasts in scales is similar to those found in mammals [24]. Using this in vitro system [35], the effects of endocrine disrupters, such as bisphenol-A [36], tributyltin [37], and polychlorinated biphenyl [38], and heavy metals (i.e., cadmium and mercury) $[22,39,40]$, on osteoblasts and osteoclasts were measured. The concentration of cadmium (even at $10^{-13} \mathrm{M}$ ) influenced osteoclastic activity in the scale [39]. Recently, we demonstrated the toxicity of gadolinium $(\mathrm{Gd})$ on osteoclasts and osteoblasts of goldfish scales [41]. Even Gd at a concentration of $10^{-13} \mathrm{M}$ suppressed osteoclastic activity at $6 \mathrm{~h}$ of incubation. Osteoblastic activity was also suppressed 
by $\mathrm{Gd}$ in the concentration range of $10^{-10}$ to $10^{-6} \mathrm{M}$ at $6 \mathrm{~h}$ of incubation [41]. Therefore, the toxicity of $\mathrm{Gd}$ to osteoclasts was comparable to that of $\mathrm{Cd}$. The osteoblastic inhibition of $\mathrm{Gd}$ was also almost equal to that of tributyltin $\left(10^{-10}\right.$ to $\left.10^{-5} \mathrm{M}\right)$ [37]. Considering the results above, fish scales are very useful for evaluating the effect of environmental pollutants on bone metabolism.

In the present study, we found that a low concentration of BaA has toxicity for the bone and liver of nibbler fish (marine teleost). As highly polluted seawater in the natural environment included $\mathrm{BaA}$ [18], we call for the prevention of PAH pollution.

\section{Conclusions}

In an in vivo experiment with nibbler fish (marine teleost) injected intraperitoneally with a low concentration of $\mathrm{BaA}$ ( 1 or $10 \mathrm{ng} / \mathrm{g}$ body weight), we found that $\mathrm{BaA}$ suppressed plasma $\mathrm{Ca}$ and $\mathrm{Pi}$ levels resulting from the inhibition of osteoclasts and osteoblasts. Furthermore, we indicated that total protein, metabolic enzymes in the liver, and T-CHO, F-CHO, and HDL-C levels significantly decreased in the BaA-injected fish. These results indicate that $\mathrm{BaA}$ may affect liver diseases in addition to bone diseases. As BaA is included in highly polluted seawater [18], we should emphasize the prevention of aquatic PAH pollution.

Author Contributions: Conceptualization, N.S. (Nobuo Suzuki), A.H., Y.T. (Yoshiaki Tabuchi) and A.K.S.; investigation, M.I.Z., N.S. (Niina Sawada), Y.K., S.O., T.S., H.M., Y.T. (Yutaka Takeuchi), T.A. and M.U.; supervision, H.F.N., H.M.M. and K.H. All authors have read and agreed to the published version of the manuscript.

Funding: This work was supported in part by a Grant for Environmental Research Projects from The Sumitomo Foundation No. 193065, by a Grant for Kurita Water and Environment Foundation No. 19B050, and by the cooperative research program of the Institute of Nature and Environmental Technology, Kanazawa University, Acceptance Nos.19010 and 19032.

Acknowledgments: We would like to thank Dr. Yachiguchi (Kanazawa University) for his support of our experiments using nibbler fish.

Conflicts of Interest: The authors declare that they have no conflicts of interest.

\section{References}

1. Lima, A.L.C.; Eglinton, T.I.; Reddy, C.M. High-resolution record of pyrogenic polycyclic aromatic hydrocarbon deposition during the 20th century. Environ. Sci. Technol. 2003, 37, 53-61. [CrossRef]

2. Lee, L.L.; Lee, J.S.C.; Waldman, S.D.; Casper, R.F.; Grynpas, M.D. Polycyclic aromatic hydrocarbons present in cigarette smoke cause bone loss in an ovariectomized rat model. Bone 2002, 30, 917-923. [CrossRef]

3. Guo, J.; Huang, Y.; Bian, S.; Zhao, C.; Jin, Y.; Yu, D.; Wu, X.; Zhang, D.; Cao, W.; Jing, F.; et al. Associations of urinary polycyclic aromatic hydrocarbons with bone mass density and osteoporosis in U.S. adults, NHANES 2005-2010. Environ. Pollut. 2018, 240, 209-218. [CrossRef]

4. Li, D.; Daler, D. Ocean pollution from land-based sources: East China Sea, China. Ambio 2004, 33, 107-113. [CrossRef]

5. Barron, M.G.; Carls, M.G.; Heintz, R.; Rice, S.D. Evaluation of fish early life-stage toxicity models of chronic embryonic exposures to complex polycyclic aromatic hydrocarbon mixtures. Toxicol. Sci. 2004, 78, 60-67. [CrossRef] [PubMed]

6. Billiard, S.M.; Timme-Laragy, A.R.; Wassenberg, D.M.; Cockman, C.; Di Giulio, R.T. The role of the aryl hydrocarbon receptor pathway in mediating synergistic developmental toxicity of polycyclic aromatic hydrocarbons to zebrafish. Toxicol. Sci. 2006, 92, 526-536. [CrossRef] [PubMed]

7. Bereiter-Hahn, J.; Zylberberg, L. Regeneration of teleost fish scale. Comp. Biochem. Physiol. Part A 1993, 105, 625-641. [CrossRef]

8. Suzuki, N.; Suzuki, T.; Kurokawa, T. Suppression of osteoclastic activities by calcitonin in the scales of goldfish (freshwater teleost) and nibbler fish (seawater teleost). Peptides 2000, 21, 115-124. [CrossRef]

9. Azuma, K.; Kobayashi, M.; Nakamura, M.; Suzuki, N.; Yashima, S.; Iwamuro, S.; Ikegame, M.; Yamamoto, T.; Hattori, A. Two osteoclastic markers expressed in multinucleate osteoclasts of goldfish scales. Biochem. Biophys. Res. Commun. 2007, 362, 594-600. [CrossRef] [PubMed] 
10. Suzuki, N.; Kitamura, K.; Nemoto, T.; Shimizu, N.; Wada, S.; Kondo, T.; Tabata, M.J.; Sodeyama, F.; Ijiri, K.; Hattori, A. Effect of vibration on osteoblastic and osteoclastic activities: Analysis of bone metabolism using goldfish scale as a model for bone. Adv. Space Res. 2007, 40, 1711-1721. [CrossRef]

11. Suzuki, N.; Somei, M.; Seki, A.; Reiter, R.J.; Hattori, A. Novel bromomelatonin derivatives as potentially effective drugs to treat bone diseases. J. Pineal Res. 2008, 45, 229-234. [CrossRef] [PubMed]

12. Mugiya, Y.; Watabe, N. Studies on fish scale formation and resorption II: Effect of estradiol on calcium homeostasis and skeletal tissue resorption in the goldfish, Carassius auratus, and the killifish, Fundulus heteroclitus. Comp. Biochem. Physiol. Part A 1977, 57, 197-202. [CrossRef]

13. Lake, J.L.; Ryba, S.A.; Serbst, J.R.; Libby, A.D. Mercury in fish scales as an assessment method for predicting muscle tissue mercury concentrations in largemouth bass. Arch. Environ. Contam. Toxicol. 2006, 50, 539-544. [CrossRef] [PubMed]

14. Camusso, M.; Vigano, L.; Balestrini, R. Bioconcentration of trace metals in rainbow trout: A field study. Ecotoxicol. Environ. Saf. 1995, 31, 133-141. [CrossRef]

15. Cobelo-García, A.; Morán, P.; Almécija, C.; Caballero, P. Historical record of trace elements (1983-2007) in scales from Atlantic salmon (Salmo salar): Study of past metal contamination from a copper mine (Ulla River, NW Iberian Peninsula). Chemosphere 2017, 188, 18-24. [CrossRef]

16. Hayakawa, K.; Onoda, Y.; Tachikawa, C.; Hosoi, S.; Yoshita, M.; Chung, S.W.; Kizu, R.; Toriba, A.; Kameda, T.; Tang, N. Estrogenic/antiestrogenic activities of polycyclic aromatic hydrocarbons and their monohydroxylated derivatives by yeast two-hybrid assay. J. Health Sci. 2007, 53, 562-570. [CrossRef]

17. Suzuki, N.; Hayakawa, K.; Kameda, T.; Toriba, A.; Tang, N.; Tabata, M.J.; Takada, K.; Wada, S.; Omori, K.; Srivastav, A.K.; et al. Monohydroxylated polycyclic aromatic hydrocarbons inhibit both osteoclastic and osteoblastic activities in teleost scales. Life Sci. 2009, 84, 482-488. [CrossRef]

18. Suzuki, N.; Sato, M.; Nassar, F.H.; Abdel-Gawad, F.K.; Bassem, S.M.; Yachiguchi, K.; Tabuchi, Y.; Endo, M.; Sekiguchi, T.; Urata, M.; et al. Seawater polluted with highly concentrated polycyclic aromatic hydrocarbons suppresses osteoblastic activity in the scales of goldfish, Carassius auratus. Zool. Sci. 2016, 33, 407-413. [CrossRef]

19. Matsunaka, T.; Nagao, S.; Inoue, M.; Mundo, R.; Tang, N.; Suzuki, N.; Ogiso, S.; Hayakawa, K. Temporal variations of polycyclic aromatic hydrocarbons in the seawater at Tsukumo Bay, Noto Peninsula, Japan, during 2014-2018. Int. J. Environ. Res. Public Health 2020, 17, 873. [CrossRef]

20. Suzuki, N.; Nakano, J.; Kawabe, K.; Toriba, A.; Hayakawa, K.; Tang, N.; Sekiguchi, T.; Tabuchi, Y.; Ikegame, M.; Shimizu, N.; et al. Benz[a]anthracene decreases plasma calcium levels resulting from influence of scale osteoclastic and osteoblastic activities in goldfish. Int. J. Zool. Inv. 2017, 3, 72-81.

21. Sato, M.; Yachiguchi, K.; Motohashi, K.; Yaguchi, Y.; Tabuchi, Y.; Kitani, Y.; Ikaria, T.; Ogiso, S.; Sekiguchi, T.; Hai, T.N.; et al. Sodium fluoride influences calcium metabolism resulting from the suppression of osteoclasts in the scales of nibbler fish Girella Punctata. Fish. Sci. 2017, 83, 543-550. [CrossRef]

22. Yachiguchi, K.; Sekiguchi, T.; Nakano, M.; Hattori, A.; Yamamoto, M.; Kitamura, K.; Maeda, M.; Tabuchi, Y.; Kondo, T.; Kamauchi, H.; et al. Effect of inorganic mercury and methylmercury on osteoclasts and osteoblasts in the scales of the marine teleost as a model system of bone. Zool. Sci. 2014, 31, 330-337. [CrossRef] [PubMed]

23. Suzuki, N.; Danks, J.A.; Maruyama, Y.; Ikegame, M.; Sasayama, Y.; Hattori, A.; Nakamura, M.; Tabata, M.J.; Yamamoto, T.; Furuya, R.; et al. Parathyroid hormone 1 (1-34) acts on the scales and involves calcium metabolism in goldfish. Bone 2011, 48, 1186-1193. [CrossRef] [PubMed]

24. Ikegame, M.; Hattori, A.; Tabata, M.J.; Kitamura, K.; Tabuchi, Y.; Furusawa, Y.; Maruyama, Y.; Yamamoto, T.; Sekiguchi, T.; Matsuoka, R.; et al. Melatonin is a potential drug for the prevention of bone loss during space flight. J. Pineal Res. 2019, 67, e12594. [CrossRef] [PubMed]

25. Danion, M.; Deschamps, M.H.; Thomas-Guyon, H.; Bado-Nilles, A.; Le Floch, S.; Quentel, C.; Sire, J.Y. Effect of an experimental oil spill on vertebral bone tissue quality in European sea bass (Dicentrarchus labrax L.). Ecotoxicol. Environ. Saf. 2011, 74, 1888-1895. [CrossRef] [PubMed]

26. Voronov, I.; Heersche, J.N.M.; Casper, R.F.; Tenenbaum, H.C.; Manolson, M.F. Inhibition of osteoclast differentiation by polycyclic aryl hydrocarbons is dependent on cell density and RANKL concentration. Biochem. Pharm. 2005, 70, 300-307. [CrossRef] [PubMed] 
27. Kuo, C.-Y.; Cheng, Y.-W.; Chen, Y.-W.; Lee, H. Correlation between the amounts of polycyclic aromatic hydrocarbons and mutagenicity of airborne particulate samples from Taichung City, Taiwan. Environ. Res. 1998, 78, 43-49. [CrossRef]

28. Wang, X.L.; Tao, S.; Dawson, R.W.; Xu, F.L. Characterizing and comparing risks of polycyclic aromatic hydrocarbons in a Tianjin wastewater-irrigated area. Environ. Res. 2002, 90, 201-206. [CrossRef]

29. Souza, T.; Jennen, D.; van Delft, J.; van Herwijnen, M.; Kyrtoupolos, S.; Kleinjans, J. New insights into BaP-induced toxicity: Role of major metabolites in transcriptomics and contribution to hepatocarcinogenesis. Arch. Toxicol. 2016, 90, 1449-1458. [CrossRef]

30. Dimai, H.P.; Linkhart, T.A.; Linkhart, S.G.; Donahue, L.R.; Beamer, W.G.; Rosen, C.J.; Farley, J.R.; Baylink, D.J. Alkaline phosphatase levels and osteoprogenitor cell numbers suggest bone formation may contribute to peak bone density differences between two inbred strains of mice. Bone 1998, 22, 211-216. [CrossRef]

31. Bower, G.; Toma, T.; Harling, L.; Jiao, L.R.; Efthimiou, E.; Darzi, A.; Athanasiou, T.; Ashrafian, H. Bariatric surgery and non-alcoholic fatty liver disease: A systematic review of liver biochemistry and histology. Obes. Surg. 2015, 25, 2280-2289. [CrossRef]

32. Shahid, S.; Masood, K. Assessing liver proteins and enzymes of medical workers exposed to ionizing radiation (IR). Clin. Exp. Med. 2018, 18, 89-99. [CrossRef] [PubMed]

33. Suzuki, N.; Kitamura, K.; Hattori, A. Fish scale is a suitable model for analyzing determinants of skeletal fragility in type 2 diabetes. Endocrine 2016, 54, 575-577. [CrossRef] [PubMed]

34. Yoshikubo, H.; Suzuki, N.; Takemura, K.; Hoso, M.; Yashima, S.; Iwamuro, S.; Takagi, Y.; Tabata, M.J.; Hattori, A. Osteoblastic activity and estrogenic response in the regenerating scale of goldfish, a good model of osteogenesis. Life Sci. 2005, 76, 2699-2709. [CrossRef] [PubMed]

35. Suzuki, N.; Hattori, A. Melatonin suppresses osteoclastic and osteoblastic activities in the scales of goldfish. J. Pineal Res. 2002, 33, 253-258. [CrossRef] [PubMed]

36. Suzuki, N.; Hattori, A. Bisphenol A suppresses osteoclastic and osteoblastic activities in the cultured scales of goldfish. Life Sci. 2003, 73, 2237-2247. [CrossRef]

37. Suzuki, N.; Tabata, M.J.; Kambegawa, A.; Srivastav, A.K.; Shimada, A.; Takeda, H.; Kobayashi, M.; Wada, S.; Katsumata, T.; Hattori, A. Tributyltin inhibits osteoblastic activity and disrupts calcium metabolism through an increase in plasma calcium and calcitonin levels in teleosts. Life Sci. 2006, 78, 2533-2541. [CrossRef]

38. Yachiguchi, K.; Matsumoto, N.; Haga, Y.; Suzuki, M.; Matsumura, C.; Tsurukawa, M.; Okuno, T.; Nakano, T.; Kawabe, K.; Kitamura, K.; et al. Polychlorinated biphenyl (118) activates osteoclasts and induces bone resorption in goldfish. Environ. Sci. Poll. Res. 2014, 21, 6365-6372. [CrossRef]

39. Suzuki, N.; Yamamoto, M.; Watanabe, K.; Kambegawa, A.; Hattori, A. Both mercury and cadmium directly influence calcium homeostasis resulting from the suppression of scale bone cells: The scale is a good model for the evaluation of heavy metals in bone metabolism. J. Bone Miner. Metab. 2004, 22, 439-446. [CrossRef]

40. Suzuki, N.; Yachiguchi, K.; Hayakawa, K.; Omori, K.; Takada, K.; Tabata, J.M.; Kitamura, K.; Endo, M.; Wada, S.; Srivastav, A.K.; et al. Effects of inorganic mercury on osteoclasts and osteoblasts of the goldfish scales in vitro. J. Fac. Agr. Kyushu Univ. 2011, 56, 47-51.

41. Suzuki, N.; Watanabe, K.; Sekimoto, A.; Urata, M.; Zanaty, M.I.; Sekiguchi, T.; Kitani, Y.; Matsubara, H.; Srivastav, A.K.; Hattori, A. Gadolinium at low concentration suppresses both osteoclastic and osteoblastic activities in the scales of goldfish. Am. J. Environ. Sci. 2019, 15, 137-144. [CrossRef]

(C) 2020 by the authors. Licensee MDPI, Basel, Switzerland. This article is an open access article distributed under the terms and conditions of the Creative Commons Attribution (CC BY) license (http://creativecommons.org/licenses/by/4.0/). 